\title{
A Commitment to Making the Library a Learning Organization
}

If everything is under control, you are going too slow.-Mario Andretti

Only a few years ago, it was common to think of rapid change in academic libraries as not being suited for their cultural framework and potentially fraught with great difficulties and hazards. Well, how things have changed! The library now may be witnessing more change than any other unit on our campuses. And the velocity of this transformation certainly will continue and likely become greater. No longer can we exercise the option of letting change develop over a long period of time. Many of the revolutionary and forcible changes are being driven by enabling technology.

\section{Users' Expectations}

The more new and expanded services we give our users, the more they want. We simply have to run faster to provide the minimal level of service expected by our users. First-year students in institutions of higher education are bringing, among other skills, a highly sophisticated level of expertise in the online environment. Many of them have been using the Internet/World Wide Web for several years. Some claim to know more about online intellectual resources than their professors. And some believe they no longer need access to the campus libraries.

Librarians are faced with doing more with less, trying to keep up with the technological changes, and struggling to understand the multifarious dimensions of change. In order for librarians to meet or exceed users' expectations, we can- not continue to rely on tra-

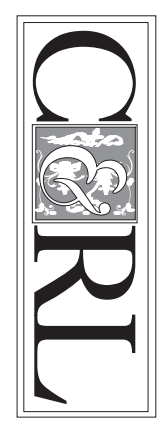
ditional methods for the delivery of service. There now is an urgency of radical adaptation to the online environment. We have to accept the fact that we now are operating in a global networked environment. Users' expectations will continue to rise, and we have to dramatically improve our skills to meet our responsibilities to the users.

\section{What Is a Learning Organization?}

There are several definitions of learning organizations; however, David Garvin offers one of the most succinct descriptions in defining a learning organization as an organization skilled at creating, acquiring, and transferring knowledge, and at modifying its behavior to reflect new knowledge and insights. This type of organization recognizes that continuous improvement requires a demonstrated commitment to learning. ${ }^{1}$ The concept of the academic library as a learning organization is not new; library staff have depended on one another and the collective learning environment of the library and its closely associated constituencies for many years. What is different today is the enlarged emphasis given to the importance of the library as a learning organization. And, quite naturally, the dramatic acceleration of change is making it necessary for libraries to perceive themselves as an oasis for continuous learning.

Peter Senge places a large amount of attention on the role of innovation in learning organizations. He presents five 
components that lead to innovation in the learning organization:

1. systems thinking, a conceptual framework developed over several years to make organizational patterns clearer;

2. personal mastery, proficiency, and commitment by the individual to one's own lifelong learning;

3. mental models, strongly held assumptions or generalizations that shape how we understand the world and our actions, sometimes without our even being conscious of them;

4. building shared vision, the ability to maintain a collective picture of a future that is sought;

5. team learning, a group discipline that begins with dialogue - the ability of team members to suspend assumptions and think together. ${ }^{2}$

Notwithstanding the abstractness of Senge's work, it does take the concept of the learning organization to a refreshing level. He believes that systems thinking is indeed the fifth discipline because its purpose is to unite all parties concerned.

\section{Who Is Responsible for Commitment?}

When one initially thinks of who is responsible for some endeavor in the library, it is normal to think of the administration. However, in a library purporting to be a learning organization, the commitment and responsibility for continuous learning activities rest on the shoulders of nearly all library employees. The library administration is responsible for setting the stage, providing leadership, and making the necessary resources available for the learning organization. "Walking the talk" also is expected of library administrators. Planning for the implementation and evaluation of the bulk of learning activities also is within the purview of administrators. Without these elements of commitment, the learning organization is doomed to fail- ure.

It is believed that organizational learning occurs best when the library staff act as learning agents for the library - that is, when they are responding to changes in the internal and external environments of the library. In short, much of the responsibility for making a library truly a learning organization depends on the library staff. Teamwork has prompted an important interchange among staff from different areas in the library. Because boundaries are collapsing within libraries, there is a sense of urgency for staff to know as much as possible about all areas in the library. We are witnessing more people working among various units in the library; thus, we have a greater interdependence among library staff. However, this type of symbiosis requires a larger spectrum of learning activities, thus fitting nicely with the concepts of a learning organization.

\section{Conclusion}

Undoubtedly, reeducation will remain at the heart of the learning organization. Goals and objectives of libraries will need to be reexamined. Time will have to be available to reflect on what one is doing. Important values must be sustained despite monumental change. The library has to become more nimble, expand its capacity, and create its future. The learning organization concept offers a wonderful and compelling challenge to improve our library staffs, which will subsequently strengthen the services provided for our users. Certainly, a win-win situation!

DONALD E. RIGGS

\section{Notes}

1. David A. Garvin, "Building a Learning Organization," Harvard Business Review 71 (July-Aug. 1993): 78-91.

2. Peter M. Senge, The Fifth Discipline: The Art and Practice of the Learning Organization (New York: Double Currency, 1990), 14. 